\title{
Quantitative Measurement of Path Loss Model Adaptation Using the Least Squares Method in an Urban DVB-T2 System
}

\author{
Pitak Keawbunsong, ${ }^{1}$ Sarun Duangsuwan $\mathbb{D}^{2},{ }^{2}$ Pichaya Supanakoon, ${ }^{1}$ \\ and Sathaporn Promwong ${ }^{1}$ \\ ${ }^{1}$ Department of Telecommunications Engineering, Faculty of Engineering, King Mongkut's Institute of Technology Ladkrabang, 1 \\ Chalongkrung Rd., Ladkrabang, Bangkok 10520, Thailand \\ ${ }^{2}$ Department of Engineering, Electronic Engineering, King Mongkut's Institute of Technology Ladkrabang, Prince of Chumphon \\ Campus, Pathio, Chumphon 86160, Thailand
}

Correspondence should be addressed to Sarun Duangsuwan; ax_sarun@hotmail.com

Received 22 July 2017; Revised 24 March 2018; Accepted 31 March 2018; Published 10 May 2018

Academic Editor: Herve Aubert

Copyright (c) 2018 Pitak Keawbunsong et al. This is an open access article distributed under the Creative Commons Attribution License, which permits unrestricted use, distribution, and reproduction in any medium, provided the original work is properly cited.

\begin{abstract}
The aim of this paper was to propose quantitative measurement of path loss model adaptation in urban radio propagation for a second-generation, terrestrial digital video broadcasting standard (DVB-T2) system. The measurement data was analyzed using data processing based on the least squares (LS) method to verify the probabilistic quantitation of realistic data measurement such as mean error (ME), root mean square error (RMSE), and standard deviation of error (SD), as well as relative error (RE). To distinguish the experimental evaluation, the researchers compared between the conventional Hata path loss model and the proposed model. The result showed that path loss based on the proposed model was more accurate in predicting the quantitative measurement of propagation data properly.
\end{abstract}

\section{Introduction}

Currently, much of the television broadcasting in countries throughout the world has been transitioned from analog to digital, usually called the DVB-T2 standard $[1,2]$. Radio regulations were launched in 2014 which provided frequencies from $510 \mathrm{MHz}$ to $790 \mathrm{MHz}$ bands. Nevertheless, a problem was found in that the coverage area was insufficient to service many clients, particularly in urban locations, which have several blind spots. Thus, a gap-fill solution is necessary to improve on these blind spots for both indoor and outdoor scenarios. Watching mobile phones that may still lack the ability to survey quality of service (QoS) is also important [3].

In the present research, radio propagation planning was done by using measurement based on an empirical model or deterministic model to predict path loss. Conventional path loss models such as the Okumura model, Hata model, or Cost-231 model are widely used to predict the probabilistic propagation of mobile communication systems [4-10]. On the other hand, DVB-T2 systems have not been the focus of many studies. In the last few years, there have been several published papers in a survey of digital broadcasting transmission techniques [11]. The results found that a problem with the transmission technique is the difficulty in controlling the multipath fading of the surroundings. Although the key requirement to develop DVB-T2 is based on the orthogonal frequency-division multiplexing (OFDM) transmission [12], automatic modulation and coding [13] or multiple input multiple output (MIMO) [14] can also be used. Measurement data in the field must also be verified. While the fixed television has been examined by the measurement results based on an empirical model [15-18], the results found that the carrier to noise ratio $(\mathrm{C} / \mathrm{N})$ minimizes to less than the requirement for the television receiver. Even though the $\mathrm{C} / \mathrm{N}$ parameter is important, the path loss measurement is also important to predict the density of multipath fading, especially in a single-frequency network (SFN) 
$[19,20]$. Therefore, the field trial has been introduced [21], where path loss varies in a range from $60 \mathrm{~dB}$ to $120 \mathrm{~dB}$ for Gaussian and Rician channels. Nevertheless, urban areas [21-23] found that the difference between the fixed reception tests was up to $130 \mathrm{~dB}$.

For the DVB-T2 system, the path loss data measurement is different from mobile communication which is not able to be directly used by the Okumura model, Hata model, or Cost-231 model. In this paper, we not only evaluate path loss data measurement but also propose close-form data processing based on the LS method for the optimization of data. The sample measurement locations are experimental regions in southern Thailand. We explain that Channel CH40 broadcasted at $626 \mathrm{MHz}$ and $\mathrm{CH} 42$ broadcasted at $642 \mathrm{MHz}$ in Surathani Province, while Channel 44 broadcasted at $658 \mathrm{MHz}$ and $\mathrm{CH} 46$ broadcasted at $674 \mathrm{MHz}$ to Songkla Province. In order to evaluate the proposed method, conventional path loss was reconsidered with probabilistic quantitation such as ME, RMSE, SD, and RE.

The rest of the paper is provided as follows: the measurement setup is described in Section 2. The proposed data processing is described in Section 3, while the results and discussion are mentioned in Section 4. Finally, a conclusion is presented in the last section of the paper.

\section{Measurement Setup}

Path loss typically depends on the characteristics of wave propagation between the transmitter and receiver, as shown in Figure 1. Propagation models are crucial for the prediction of radio channels. The deterministic model is usually based on the ray-optical method. This model offers excellent accuracy and is able to provide additional parameters such as small-scale fading and delay spread. However, the disadvantages include large computation time and the conditions being insufficient.

The empirical model is provided based on observation and measurement. This model can be classified, namely, as time dispersive or non-time dispersive: time dispersive is modeled to predict the path loss from channel measurement results. On the other hand, non-time dispersive predicts mean path loss from the function as distance, antenna height, and so on, such as the Okumura model and Hata model. This paper considers the measurement field trial based on the empirical model, both time dispersive and nontime-dispersive evaluation where the detail of locations is Songkla and Surathani Provinces, Thailand. Note that the transmitter in Songkla Province is located at a latitude of $70^{\prime} 57.95^{\prime \prime}$ and longitude of $10031^{\prime} 12.17^{\prime \prime}$ at a height of about 417 meters above sea level and the transmitter in Surathani Province is located at a latitude of $95^{\prime} 32.77^{\prime \prime}$ and longitude of $9920^{\prime} 55.59^{\prime \prime}$ at a height of about 244 meters above sea level.

Figure 2 shows a block diagram of a DVB-T2 transmission system and a design for the reception system. The reception system consists of $-3 \mathrm{dBi} \mathrm{Rx}$ antenna vertical monopole connected to a channel filter which is set to channels $\mathrm{CH} 40, \mathrm{CH} 42, \mathrm{CH} 44$, and $\mathrm{CH} 46$ to cancel other emissions' interference with the desired signal. The received signal is recorded by using an IQ recorder as the baseband IQ sample data processing stage. The measurement data is automatically recorded (received signal) and post-data processing is done by an optimized path loss model.

The transmission system consists of the following:

(1) Input stream processor: this part includes the transport stream (TS), generic encapsulated stream (GSE), generic continuous stream (GCS), generic fixed-length packetized stream (GFPS), and physical layer pipes (PLPs). These are stream systems to transmit higher data broadcasting.

(2) Block interleaving and coding modulation (BICM): this part includes all the interleaving, coding, and modulation steps carried out over each BB frame of PLPs. The interleaving is an outer encoder and an inner encoder (LDPC). The LDPC is an option for increasing the robustness of data transmission against channel time-varying disturbance. The encoding uses LDPC FEC and modulation is up to 256 QAM.

(3) Frame mapper: this part is in charge of allocating the packets from PLPs to the data carriers of the OFDM symbols. DVB-T2 offers six FFT sizes of $1 \mathrm{~K}, 2 \mathrm{~K}, 4 \mathrm{~K}$, $8 \mathrm{~K}, 16 \mathrm{~K}$, and $32 \mathrm{~K}$ and seven guard interval fractions as $1 / 128,1 / 32,1 / 16,19 / 256,1 / 8,19 / 128$, and $1 / 4$.

(4) Modulator: this part includes an OFDM function such as active constellation extension (ACE) and tone reservation (TR) to control the peak-to-average power ratio (PAPR).

The reception system consists of the following:

(1) $\mathrm{Rx}$ antenna: this part is an antenna receiver that is used in the measurement field and is connected to a channel filter.

(2) IQ recorder: this part collects the received signal and stores on a hard disk as baseband IQ samples for a posterior off-line processing stage.

(3) Measurement information: this part collects location from a GPS system as parameters of the measurement.

(4) Postprocessing: this part is data processing.

The measurement locations are shown from a satellite map of both Songkla and Surathani in Figures 3 and 4, respectively. In addition, the measurement test was performed by a mobile drive test in Figure 5, where the speed of the car did not exceed $40 \mathrm{~km}$ per hour and provided $\mathrm{C}$ model HD RANGER+ which used a GPS and USB drive for data collection. The commercial omnidirectional antenna from a Spectrum model was used as a receiver dipole antenna with $-3 \mathrm{~dB}$ of relative gain. The receiver antenna was mounted on the roof of the car, where the antenna height was set to $2 \mathrm{~m}$ above the ground. In the measurement setup, the number of frequency sweeping points was 3001, while 


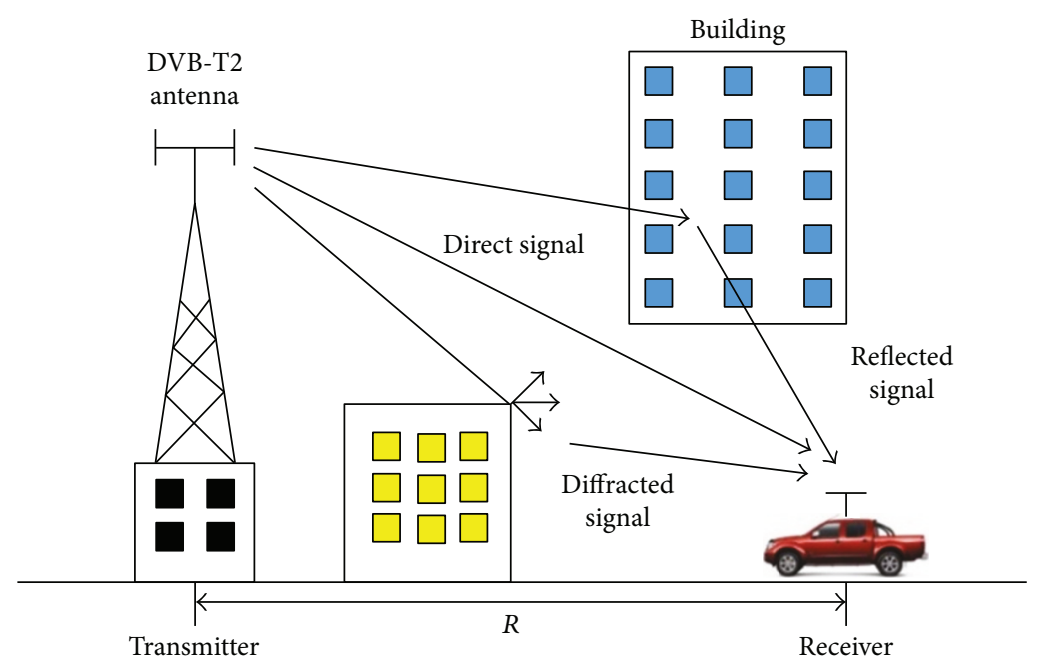

Figure 1: Measurement model for path loss in urban channel propagation.

DVB-T2 trasmission system

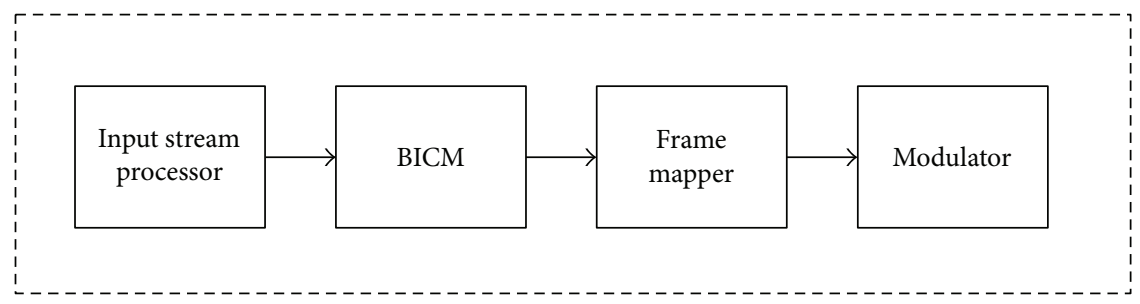

DVB-T2 reception system

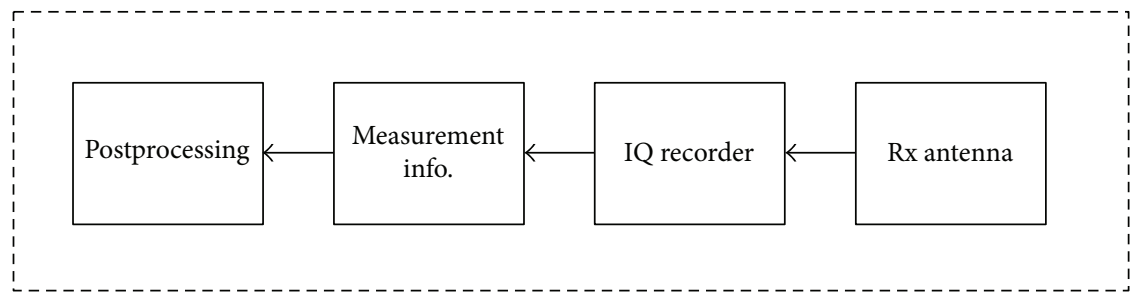

FIGURE 2: Block diagram of DVB-T2 transmission and reception systems.

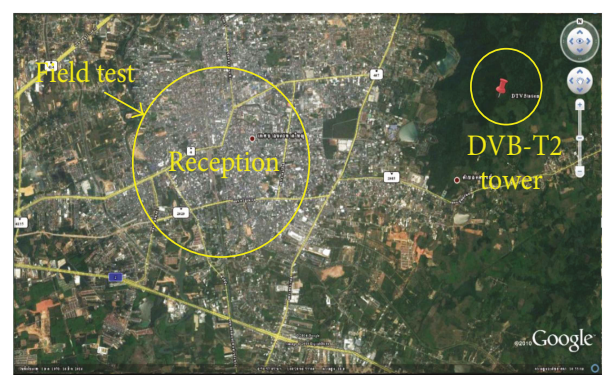

Figure 3: Measurement locations in Songkla Province.

resolution bandwidth was $10 \mathrm{kHz}$, and frequency band ranged from $510 \mathrm{MHz}$ to $790 \mathrm{MHz}$. Note that the distance between the transmitting antennas to the receiving antenna was $2 \mathrm{~km}$ to $7 \mathrm{~km}$. The parameters of DVB-T2 transmitter system are shown in Table 1.

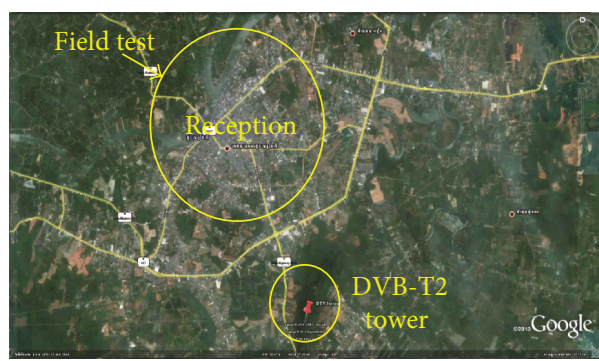

Figure 4: Measurement locations in Surathani Province.

\section{Path Loss Modeling-Based LS Method}

This section proposes the data processing for path loss modeling. In the procedure, the data measurement collection is firstly conducted to analyze by using the conventional 


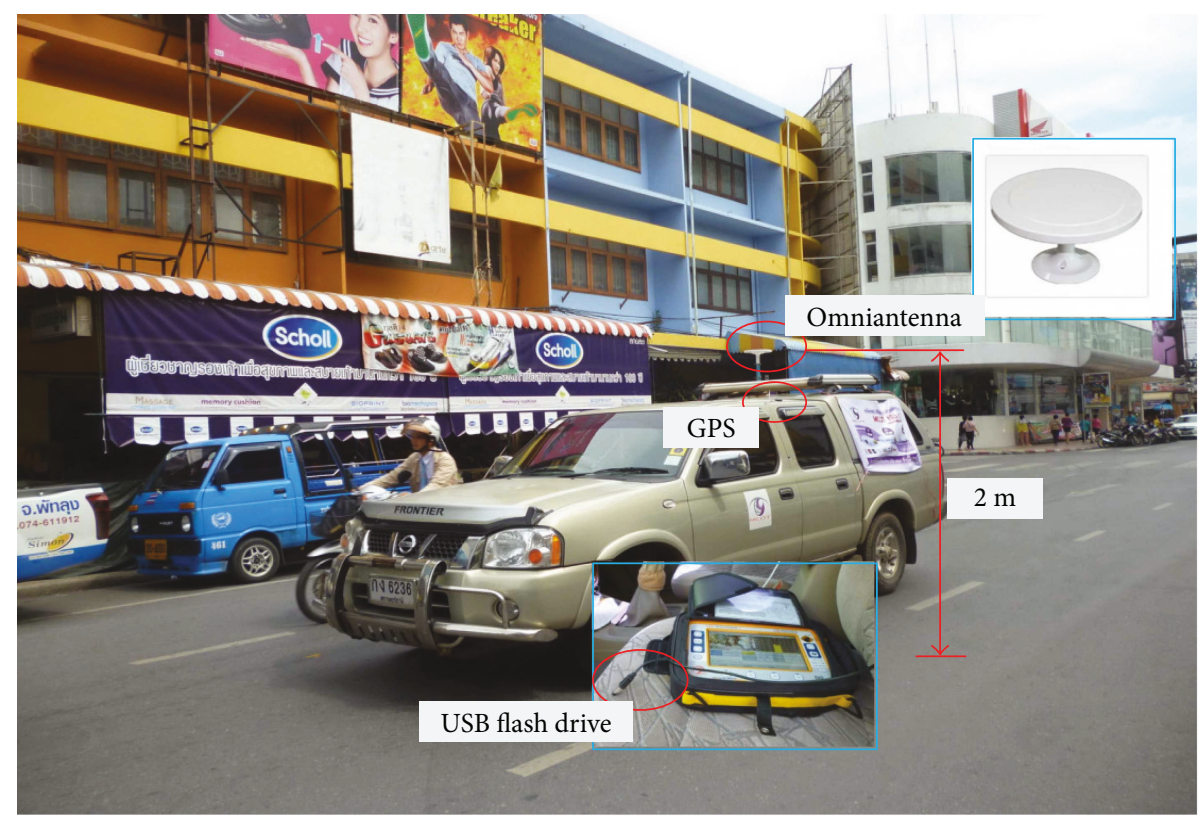

Figure 5: Measurement setup in urban areas.

TABle 1: Parameters of broadcasting at the transmitter.

\begin{tabular}{lc}
\hline Parameter & Value \\
\hline FFT size & $16 \mathrm{~K}$ \\
Guard interval & $19 / 128$ \\
Modulation & 64 QAM \\
FEC code rate & $3 / 5$ \\
\hline
\end{tabular}

path loss model. Secondly, a process of optimization is obtained to estimate using the least squares method and evaluate the validation of data integration. Finally, statistical analysis parameters such as ME, RMSE, SD, and RE are used to evaluate a comparison between the optimized path loss model and the conventional path loss model. In [4], they claim that the Hata model is a significant improvement over the Okumura model for the prediction of path loss. Propagation in different geographical regions is taken into consideration using correction factors that have been empirically derived. The starting point in path loss prediction is the propagation in an urban area. Path loss models are generally given in terms of the median loss rather than the mean loss. Also, path losses are given in terms of the effective height of the transmitting antenna and the height of the receiving antenna. Typically, the transmitting antenna is mounted on the top of existing buildings at a distance between $1 \mathrm{~km}$ and $20 \mathrm{~km}$, frequency bands from $150 \mathrm{MHz}$ to $1500 \mathrm{MHz}$, and an antenna height of $1 \mathrm{~m}$ to $10 \mathrm{~m}$.

In a conventional Hata model, path loss is given by

$$
\begin{aligned}
\mathrm{PL}(\mathrm{dB})= & 69.55+26.16 \log _{10} f_{\mathrm{c}}-13.82 \log _{10} h_{\mathrm{t}} \\
& +\left(44.9-6.55 \log _{10} h_{\mathrm{t}}\right) \log _{10} R-E
\end{aligned}
$$

where $E$ represents a large scale, medium scale, and small scale; $h_{\mathrm{t}}$ and $h_{\mathrm{r}}$ denote the antenna height of the transmitter and receiver; $f_{c}$ is the center of frequency; and $R$ is the distance. However, for the large scale, when $f_{c} \geq 400 \mathrm{MHz}$,

$$
E=3.2\left[\log _{10}\left(11.75 h_{\mathrm{r}}\right)\right]^{2}-4.97
$$

For the medium and small scales,

$$
E=\left[\log _{10}\left(f_{\mathrm{c}}\right)-0.7\right] h_{\mathrm{r}}-\left[1.56 \log _{10}\left(f_{\mathrm{c}}\right)-0.8\right] .
$$

The optimized path loss is based on using the LS method to find the estimated values $a$ and $b$, the sum of the square distance from the actual measured data $y_{i}$; we can obtain the estimated data of the new path loss model, which is

$$
(a, b)=\arg \min _{(a, b)} \sum_{i=1}^{N}\left[y_{i}-\left(a+b x_{i}\right)\right]^{2},
$$

where $i=1,2, \ldots, N$ is the number of total data collection and $x_{i}$ is the value from the conventional path loss model.

Mathematically, the LS method conditions are estimated by using a linear regression strategy that is given by

$$
\begin{aligned}
& \frac{\partial}{\partial a} \sum_{i=1}^{n}\left[y_{i}-\left(a+b x_{i}\right)\right]^{2}=0, \\
& \frac{\partial}{\partial b} \sum_{i=1}^{n}\left[y_{i}-\left(a+b x_{i}\right)\right]^{2}=0 .
\end{aligned}
$$

Suppose that $a$ and $b$ are the solution of the substitutive conditions (5) and (6), then the relationship between the variables $y$ and $x$ by using the regression line as $y=a+b x$ which 
is called the curve fitting. To solve the unknown variables $a$ and $b$, then, we get

$$
y_{i}=a^{*}+b\left(x_{i}-\bar{x}\right)+\varepsilon_{i}
$$

where $a=a^{*}-b \bar{x}, \bar{x}$ is the estimation value from the path loss model, and $\varepsilon$ is the random error.

The differential equation is normalized by

$$
\begin{gathered}
\frac{\partial}{\partial a^{*}} \sum_{i=1}^{n}\left[y_{i}-\left(a^{*}+b\left(x_{i}-\bar{x}\right)\right)\right]^{2}=0, \\
\frac{\partial}{\partial b} \sum_{i=1}^{n}\left[y_{i}-\left(a^{*}+b\left(x_{i}-\bar{x}\right)\right)\right]^{2}=0 .
\end{gathered}
$$

Taking the partial derivatives with response to $a$ and $b$, we can obtain

$$
\begin{aligned}
\sum_{I=1}^{N}\left[y_{i}-\left(a^{*}+b\left(x_{i}-\bar{x}\right)\right)\right] & =0, \\
\sum_{i=1}^{N}\left[y_{i}-\left(a^{*}+b\left(x_{i}-\bar{x}\right)\right)\right]\left(x_{i}-\bar{x}\right) & =0, \\
\sum_{i=1}^{N} y_{i}=n a^{*}+\sum_{i=1}^{n} b\left(x_{i}-\bar{x}\right) & =n a^{*} .
\end{aligned}
$$

Therefore, $a^{*}=(1 / N) \sum_{i=1}^{N} y_{i}=\bar{y}$, substituting $a^{*}$ by $\bar{y}$ in (10) that is expressed by

$$
\sum_{i=1}^{N}\left[y_{i}-\left(\bar{y}+b\left(x_{i}-\bar{x}\right)\right)\right]\left(x_{i}-\bar{x}\right)=0 .
$$

Note that $a$ and $b$ can be the solution for the substitution of (5) and (6). Thus, it can be written as

$$
a=\frac{\sum_{i=1}^{n}\left(y_{i}-\bar{y}\right)\left(x_{i}-\bar{x}\right)}{\sum_{i=1}^{n}\left(x_{i}-\bar{x}\right)^{2}}
$$

and $b=\bar{y}-a \bar{x}$ is the substituting condition.

Finally, the validation of path loss measured results is data processed by the statistical properties. ME, RMSE, SD, and $\mathrm{RE}$ are significantly proposed in this paper.

For the statistical properties, the relative expression is given by

$$
\begin{aligned}
\mathrm{ME} & =\frac{1}{N} \sum_{i=1}^{N}\left|y_{i}-(a+b) x_{i}\right|, \\
\mathrm{RMSE} & =\sqrt{\frac{1}{N} \sum_{i=1}^{N}\left|y_{i}-(a+b) x_{i}\right|^{2},} \\
\mathrm{SD} & =\sqrt{\frac{1}{N} \sum_{i=1}^{N}\left|y_{i}-(a+b) x_{i}-\mathrm{ME}\right|^{2},} \\
\mathrm{RE} & =\frac{\left|\mathrm{PL}_{\mathrm{o}}-\mathrm{PL}_{\mathrm{m}}\right|}{\left|\mathrm{PL}_{\mathrm{o}}\right|},
\end{aligned}
$$

where $\mathrm{PL}_{\mathrm{o}}$ is the data processing path loss model and $\mathrm{PL}_{\mathrm{m}}$ is the data measurement.

\section{Quantitative Evaluation}

The measurement results, which were taken in two different environments in urban areas of both Surathani and Songkla Provinces, are shown in Figures 6(a)-6(d), respectively. This was done in order to compute the stochastic propagation parameters and evaluate the accuracy of the proposed method.

Figures 6(a) and 6(b) show the path loss results at broadcasted $\mathrm{CH} 40$ and $\mathrm{CH} 42$ in Surathani. The distance between the transmitter and receiver was $2 \mathrm{~km}$ to $7 \mathrm{~km}$. It was observed that the measured data was scattered from the minimum path loss $100 \mathrm{~dB}$ to the maximum path loss $160 \mathrm{~dB}$, which had a variance over $40 \mathrm{~dB}$, while the empirical path loss model in the blue line by the Hata model was not close to the measured data as much as the proposed method in the violet line. By definition, the least squares method has a zero mean error. Note that the propagation errors are calculated as the difference between predictions and measurements. Hence, significant positive parameters $a$ and $b$, as shown in Table 2, indicate that the optimized Hata model in general is actually a path loss measurement in a DVB-T2 system in an urban area. However, in order to distinguish between the optimization path loss and the conventional Hata model, the mean error (ME) values were obtained from substitutive conditions in (13), as summarized in Table 3. It clearly shows that both the free-space model and the Hata model predict a lower path loss exponent than does the proposed method for urban environments. Consequently, path loss predictions made by the free-space and conventional Hata models are grossly lower estimations than the actual data measurement. Figures 6(c) and 6(d) show path loss results at radio broadcasted $\mathrm{CH} 44$ and $\mathrm{CH} 46$ in Songkla. Note that the measured data is scattered from the minimum path loss curve $110 \mathrm{~dB}$ to the maximum path loss $160 \mathrm{~dB}$, which has a variance over $50 \mathrm{~dB}$. In addition, it mentions that the empirical path loss model in the blue line for the Hata model is still not close to the measured data as much as the proposed method in the violet line. The results of RMSE are shown in Table 4, which distinguishes between the Hata model and the proposed method compared with the data measurement. Also, the SD and RE of the proposed method in Table 5 and Table 6 are very satisfactory for use with the directly conventional Hata model.

\section{Conclusion}

The main purpose of this paper was to propose optimized path loss modeling based on stochastic quantitation and measurement data for channel propagation in two different urban areas for second-generation, terrestrial digital video broadcasting standard (DVB-T2) for evaluation. We consider path loss by using data processing, by which the LS 


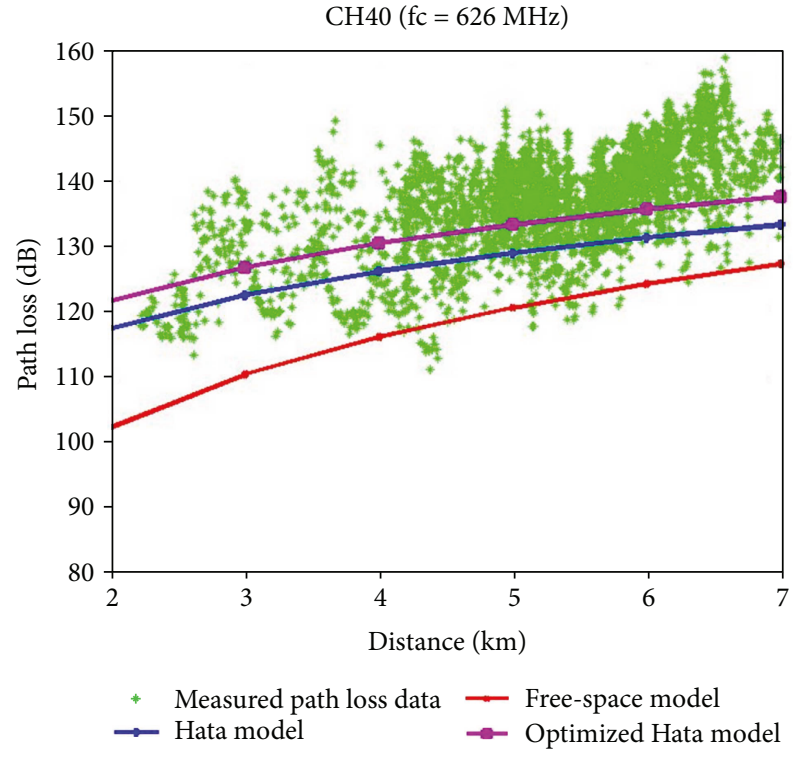

(a)

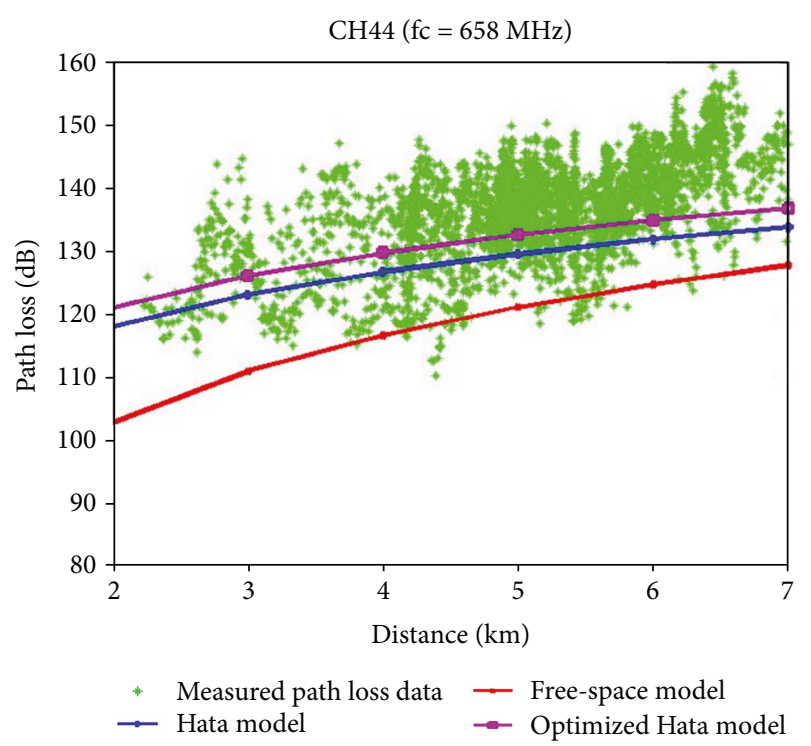

(c)

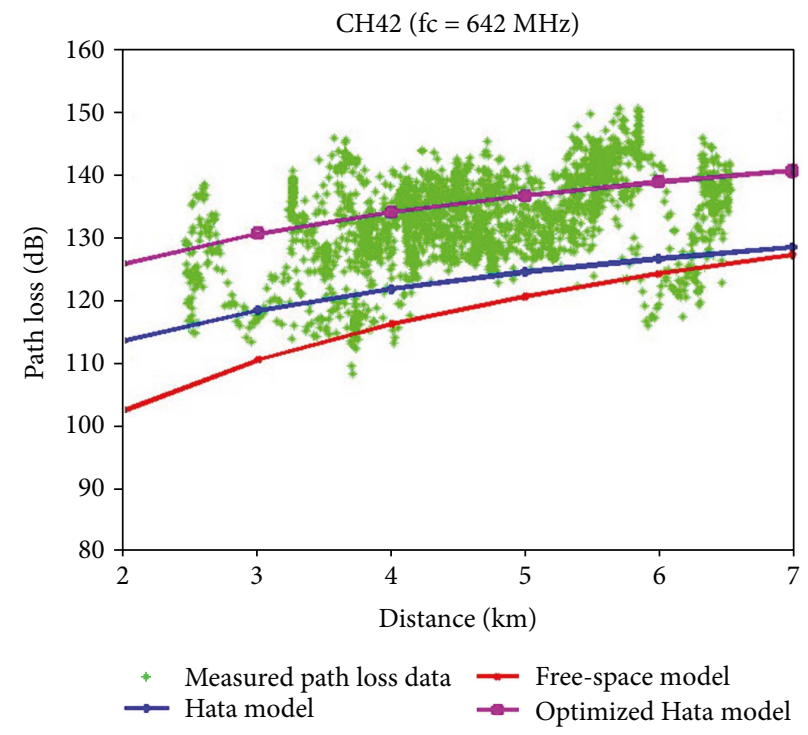

(b)

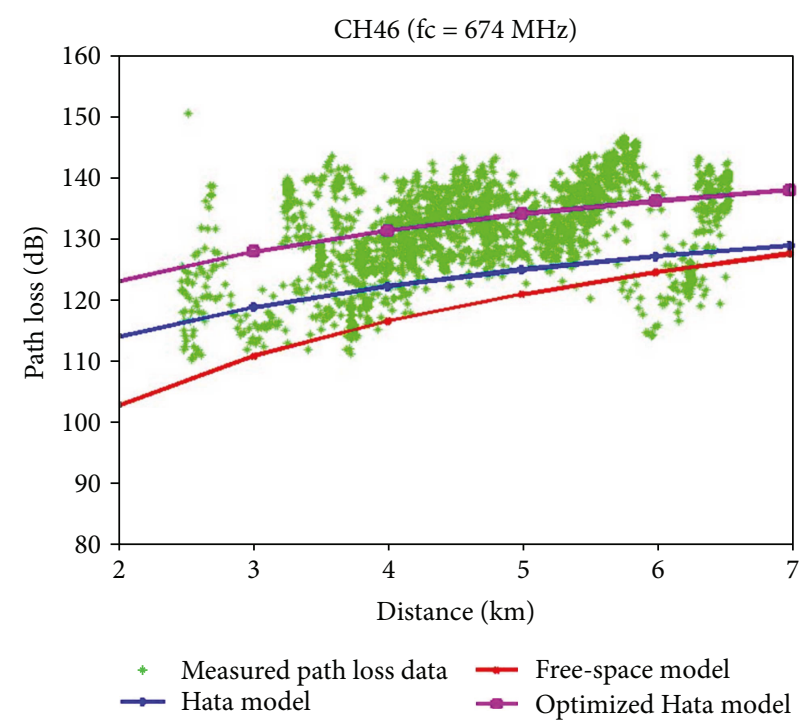

(d)

FIgURE 6: Measurement data of path loss curves between Songkla and Surathani Province.

TABLE 2: LS calculative values.

\begin{tabular}{lcccc}
\hline \multirow{2}{*}{ Location } & \multirow{2}{*}{ Channel } & \multirow{2}{*}{ Frequency } & \multicolumn{2}{c}{ Least square $(\mathrm{dB})$} \\
& & & \multicolumn{1}{c}{$b$} \\
\hline \multirow{2}{*}{ Surathani } & 40 & $626 \mathrm{MHz}$ & 112.725 & 4.408 \\
& 42 & $642 \mathrm{MHz}$ & 112.034 & 4.564 \\
\multirow{3}{*}{ Songkla } & 44 & $658 \mathrm{MHz}$ & 117.622 & 3.222 \\
Average & 46 & $674 \mathrm{MHz}$ & 114.983 & 3.598 \\
& & & 114.341 & 3.948 \\
\hline
\end{tabular}

method has been proposed. Experimental results have been discussed based on the stochastic parameters such as ME, RMSE, SD, and RE. It can be concluded that optimized
TABLE 3: ME calculative values.

\begin{tabular}{lcccc}
\hline \multirow{2}{*}{ Location } & \multirow{2}{*}{ Channel/frequency } & \multicolumn{3}{c}{ ME (dB) } \\
& & Free space & Hata [4] & Proposed \\
\hline \multirow{2}{*}{ Surathani } & $40 / 626 \mathrm{MHz}$ & 49.975 & 7.823 & 5.610 \\
& $42 / 642 \mathrm{MHz}$ & 49.354 & 7.447 & 5.890 \\
\multirow{3}{*}{ Songkla } & $44 / 658 \mathrm{MHz}$ & 46.190 & 9.806 & 5.500 \\
\multirow{2}{*}{ Average } & $46 / 674 \mathrm{MHz}$ & 44.979 & 8.811 & 5.321 \\
\hline
\end{tabular}

path loss modeling based on stochastic quantitation is more accurate for predicting channel propagation in the DVB-T2 system. 
TABLE 4: RMSE calculative values.

\begin{tabular}{lcccc}
\hline \multirow{2}{*}{ Location } & \multirow{2}{*}{ Channel/frequency } & \multicolumn{3}{c}{ RMSE (dB) } \\
& & Free space & Hata [4] & Proposed \\
\hline \multirow{2}{*}{ Surathani } & $40 / 626 \mathrm{MHz}$ & 50.424 & 9.245 & 6.872 \\
& $42 / 642 \mathrm{MHz}$ & 49.834 & 8.896 & 7.244 \\
\multirow{3}{*}{ Songkla } & $44 / 658 \mathrm{MHz}$ & 46.635 & 11.065 & 6.717 \\
& $46 / 674 \mathrm{MHz}$ & 45.482 & 10.158 & 6.837 \\
Average & & 48.094 & 9.841 & 6.917 \\
\hline
\end{tabular}

TABLE 5: SD calculative values.

\begin{tabular}{lcccc}
\hline \multirow{2}{*}{ Location } & Channel/frequency & \multicolumn{3}{c}{ SD (dB) } \\
& & Free space & Hata [4] & Proposed \\
\hline \multirow{2}{*}{ Surathani } & $40 / 626 \mathrm{MHz}$ & 6.777 & 4.929 & 3.971 \\
& $42 / 642 \mathrm{MHz}$ & 6.960 & 4.869 & 4.219 \\
\multirow{2}{*}{ Songkla } & $44 / 658 \mathrm{MHz}$ & 6.501 & 5.131 & 4.680 \\
& $46 / 674 \mathrm{MHz}$ & 6.810 & 5.056 & 4.295 \\
Average & & 6.762 & 4.996 & 4.291 \\
\hline
\end{tabular}

TABLE 6: RE calculative values.

\begin{tabular}{lcccc}
\hline \multirow{2}{*}{ Location } & \multirow{2}{*}{ Channel/frequency } & \multicolumn{3}{c}{ RE (dB) } \\
& Free space & Hata [4] & Proposed \\
\hline \multirow{2}{*}{ Surathani } & $40 / 626 \mathrm{MHz}$ & 0.302 & 0.048 & 0.017 \\
& $42 / 642 \mathrm{MHz}$ & 0.364 & 0.043 & 0.021 \\
\multirow{3}{*}{ Songkla } & $44 / 658 \mathrm{MHz}$ & 0.348 & 0.068 & 0.025 \\
& $46 / 674 \mathrm{MHz}$ & 0.341 & 0.058 & 0.012 \\
Average & & 0.339 & 0.054 & 0.019 \\
\hline
\end{tabular}

\section{Conflicts of Interest}

The authors declare that they have no conflicts of interest.

\section{Acknowledgments}

The authors would like to thank the Thai Public Broadcasting Service (TPBS) for the supporting information about their systems and base stations. The authors would also like to acknowledge MCOT Public Company Limited for providing support to fund the site survey.

\section{References}

[1] I. Eizmendi, M. Velez, D. Gomez-Barquero et al., "DVB-T2: The second generation of terrestrial digital video broadcasting system," IEEE Transactions on Broadcasting, vol. 60, no. 2, pp. 258-271, 2014.

[2] M. El-Hajjar and L. Hanzo, "A survey of digital television broadcast transmission techniques," IEEE Communication Surveys and Tutorials, vol. 15, no. 4, pp. 1924-1949, 2013.

[3] C. Hellge, T. Wiegand, E. Torre, D. Gomez-Barquero, and T. Schierl, "Efficient HDTV and 3DTV services over DVBT2 using multiple PLPs with layered media," IEEE Communications Magazine, vol. 51, no. 10, pp. 76-82, 2013.
[4] N. Cota, A. Serrador, P. Vieira, A. R. Beire, and A. Rodrigues, "On the use of Okumura-Hat a propagation model on railway communications," in Proceedings of the 16th International Symposium on Wireless Personal Multimedia Communications (WPMC), pp. 1-5, Atlantic City, NJ, USA, 2013.

[5] A. Sultan, "Empirical correction of the Okumura-Hata model for the $900 \mathrm{MHz}$ band in Egypt," in Proceedings of the Third International Conference on Communication and Information Technology (ICCIT), pp. 386-390, Beirut, Lebanon, 2012.

[6] N. Blaunstein, Y. Cohen, and M. Hayakawa, "Prediction of fading phenomena in land-satellite communication links," Radio Science, vol. 45, no. 6, pp. 1-13, 2010.

[7] T. K. Sarkar, W. Dyab, M. N. Abdallah et al., "Electromagnetic macro modeling of propagation in mobile wireless communication: theory and experiment," IEEE Antennas and Propagation Magazine, vol. 54, no. 6, pp. 17-43, 2012.

[8] B. H. Fleury and P. E. Leuthold, "Radiowave propagation in mobile communications: an overview of European research," IEEE Communications Magazine, vol. 34, no. 2, pp. 70-81, 1996.

[9] Z. Y. Wang, R. H. Jin, Y. Jin, J. P. Geng, X. L. Liang, and Y. S. Zheng, "Propagation model for mobile digital TV coverage under viaduct," Radio Science, vol. 45, no. 3, pp. 1-9, 2010.

[10] A. Bronshtein, R. Mazar, and I.-T. Lu, "Analysis of foliage effects on mobile propagation in dense urban environments," Radio Science, vol. 35, no. 4, pp. 941-953, 2000.

[11] M. El-Hajjar and L. Hanzo, "A survey of digital television broadcast transmission techniques," IEEE Communications Surveys \& Tutorials, vol. 15, no. 4, pp. 1924-1949, 2013.

[12] E. Hong, Y. Park, S. Lim, and D. Har, "Adaptive phase rotation of OFDM signals for PAPR reduction," IEEE Transactions on Consumer Electronics, vol. 57, no. 4, pp. 1491-1495, 2011.

[13] A. Vigato, S. Tomasin, L. Vangelista, V. Mignone, N. Benvenuto, and A. Morello, "Coded decision directed demodulation for second generation digital video broadcasting standard," IEEE Transactions on Broadcasting, vol. 55, no. 3, pp. 607-615, 2009.

[14] J. H. Seo, T. J. Jung, H. M. Kim, and D. S. Han, "Improved polarized $2 \times 2$ MIMO spatial multiplexing method for DVBNGH system," IEEE Transactions on Broadcasting, vol. 61, no. 4, pp. 729-733, 2015.

[15] A. Gifuni, G. Ferrara, M. Migliaccio, and A. Sorrentino, "Mode-stirred reverberating chamber Doppler spectra: multifrequency measurements and empirical model," IET Microwaves, Antennas \& Propagation, vol. 8, no. 15, pp. 1356-1362, 2014.

[16] N. Alsindi, B. Alavi, and K. Pahlavan, "Empirical pathloss model for indoor geolocation using UWB measurements," Electronics Letters, vol. 43, no. 7, p. 370, 2007.

[17] R. C. French, "Error rate predictions and measurements in the mobile radio data channel," IEEE Transactions on Vehicular Technology, vol. 27, no. 3, pp. 110-116, 1978.

[18] S.-P. Sheng, M. Liu, and R. Saigal, "Data-driven channel modeling using spectrum measurement," IEEE Transactions on Mobile Computing, vol. 14, no. 9, pp. 1794-1805, 2015.

[19] G. Guerra, P. Angueira, M. M. Velez et al., "Field measurement based characterization of the wideband urban multipath channel for portable DTV reception in single frequency networks," IEEE Transactions on Broadcasting, vol. 51, no. 2, pp. 171-179, 2005. 
[20] C. Li, S. Telemi, X. Zhang, R. Brugger, I. Angulo, and P. Angueira, "Planning large single frequency networks for DVB-T2," IEEE Transactions on Broadcasting, vol. 61, no. 3, pp. 376-387, 2015.

[21] N. Suwansukho, S. Promwong, and M. Chamchoy, "Evaluation of DVB-T2 transmission channel in Bangkok, Thailand," in International Conference on Digital Arts, Media and Technology (ICDAMT), pp. 79-84, Chiang Mai, Thailand, 2017.

[22] I. Eizmendi, G. Prieto, G. Berjon-Eriz, I. Landa, and M. Velez, "Empirical DVB-T2 thresholds for fixed reception," IEEE Transactions on Broadcasting, vol. 59, no. 2, pp. 306-316, 2013.

[23] A. N. Cadavid, R. D. Rojas, and M. P. Bernal, "Digital terrestrail television measurement and coverage models comparison: evaluation of measurements and simulations on urban environment for DVB-T2 signals," in IEEE International Symposium on Antennas and Propagations (APSURSI), pp. 12571258, Fajardo, Puerto Rico, 2016. 


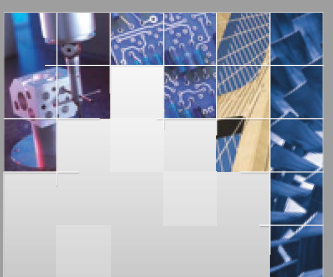

\section{Enfincering}
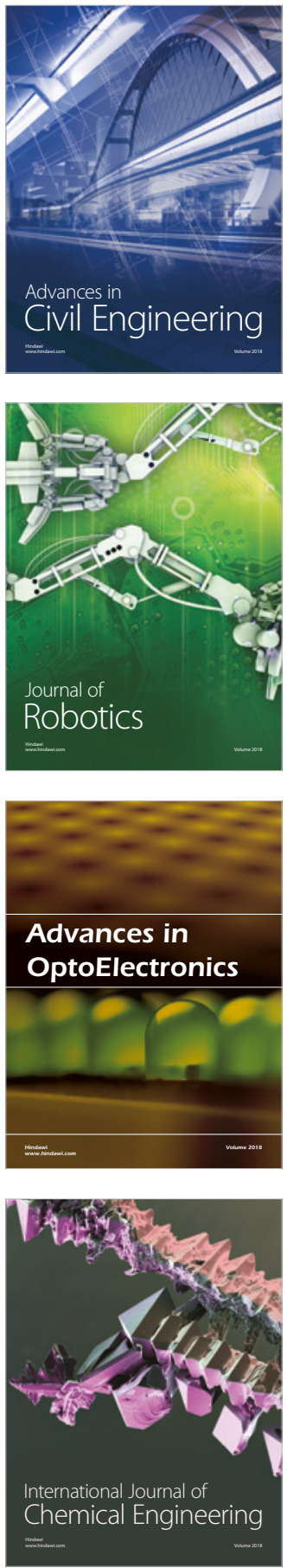

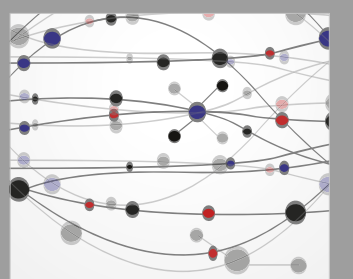

\section{Rotating \\ Machinery}

The Scientific World Journal

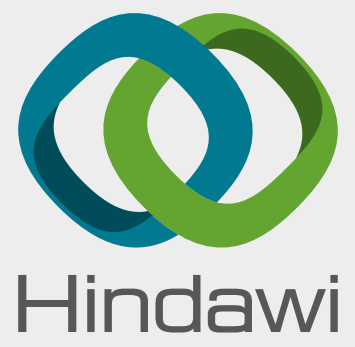

Submit your manuscripts at

www.hindawi.com
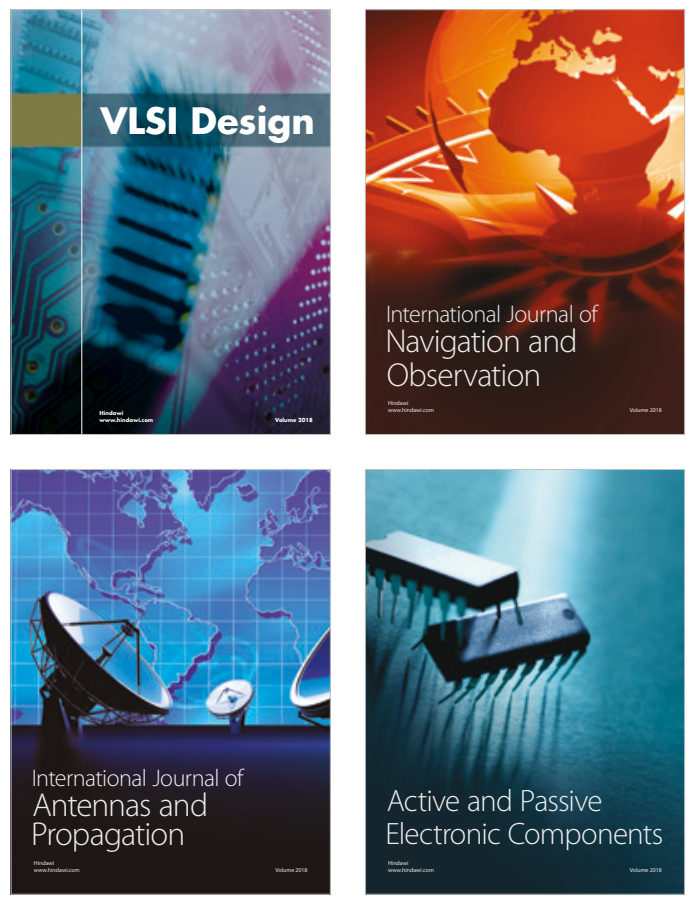
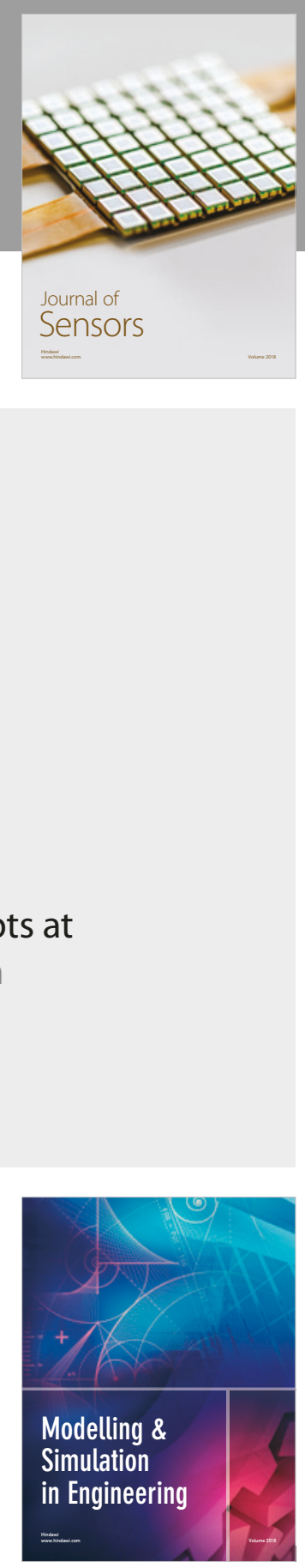

\section{Advances \\ Multimedia}
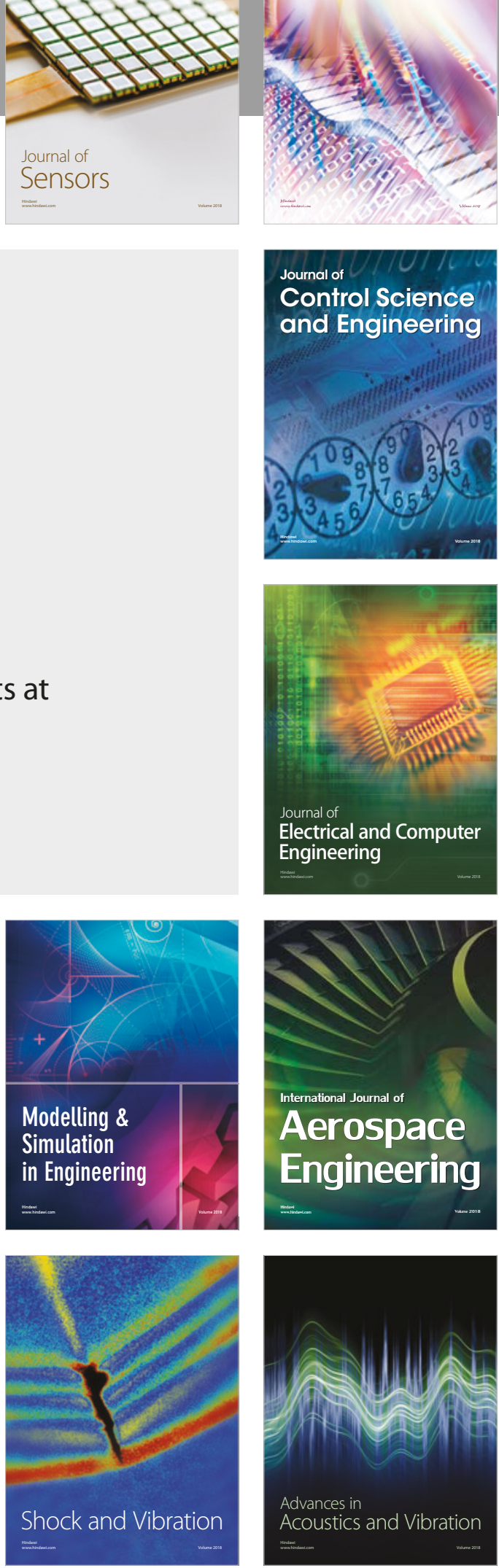